\title{
Polyimide foam composites with nano-boron nitride (BN) and silicon carbide (SiC) for latent heat storage
}

\author{
Marialaura Clausi $^{1,2} \cdot$ Muhammad Zahid $^{2,3} \cdot$ Amirreza Shayganpour $^{2} \cdot$ Ilker S. Bayer $^{2}(\mathbb{0}$
}

Received: 4 October 2021 / Revised: 14 January 2022 / Accepted: 19 January 2022 / Published online: 31 January 2022

(c) The Author(s) 2022

\begin{abstract}
Leaching and instability in wax-based phase change materials (PCMs) are serious application problems. Herein, we developed paper-like $(\sim 100 \mu \mathrm{m})$ flexible, composite PCMs by hydraulic compression of 1-cm-thick polyimide foams between an aluminum foil and a (nano) ceramic composite Parafilm ${ }^{\circledR}$. An unfilled PCM film placed between the foam and the aluminum surface ensured strong adhesion between the collapsed foam and the metal. Different concentrations of nano-BN and micro-SiC particles were compounded into Parafilm ${ }^{\circledR}$ in order to optimize the thermal performance. Based on infrared imaging, the monoliths containing $30 \mathrm{wt} \%$ micro-SiC outperformed all other systems including $\mathrm{BN} / \mathrm{SiC}$ hybrids. The next best thermal performance was observed with the $60 \mathrm{wt} \%$ nano-BN composite. Due to compression, the cellular structure of the polyimide foams collapsed irreversibly while being impregnated by the PCMs from both sides. High- $k$ fillers improved impregnation into the collapsed foam and enabled excellent shape stability and leakage prevention.
\end{abstract}

Keywords Polyimide $\cdot$ Phase change material $\cdot$ Boron nitride $\cdot$ Silicon carbide $\cdot$ Foam

\section{Introduction}

Polyimide (PI) foams were first produced and commercialized by EIDuPont de Nemours (Dupont) company in the 1960s [1, 2]. Ever since, the types and applications of PI foams have expanded significantly due to their unique properties, such as high thermal stability, thermal and acoustic insulation, chemical inertness, and lightweight [3]. Many technological applications have also been realized in the fields of aircraft and spacecraft design, advanced military materials, marine technologies, and high-speed trains to name a few [4-6]. Certain PI foams can even operate at temperatures exceeding $300^{\circ} \mathrm{C}$. These PI foams are synthesized from monomers such as 2,3,3',4'-biphenyltetracarboxylicdianhydride (a-BPDA) and p-phenylenediamine ( p-PDA) [7]. Other high

Ilker S. Bayer

ilker.bayer@iit.it

1 Strategy \& Technological Innovation and Leonardo Labs, Helicopters Division, Leonardo S.p.A, Cascina Costa (VA), 21017 Samarate, Italy

2 Smart Materials, Istituto Italiano di Tecnologia, 16163 Genova, Italy

3 Leonardo R\&D Labs, Aerostructure Division, Leonardo S.p.A, 74023 Grottaglie, Italy performance foams were made with monomers like pyromellitic dianhydride (PMDA) and polyaryl polymethylene isocyanate (PAPI) [8]. One can refer to a recent review article that discusses several typical fabrication methods of PI foams and the related synthesis mechanisms. Therein, the advantages and disadvantages of the preparation methods are also compared [9].

More recently, PI foams have been used in the development of high performance functional composites or nanocomposites [10]. For instance, a lightweight and robust carbon nanotube, (CNT)/PI foam was developed for efficient and heat-resistant electromagnetic (EMI) shielding [11] application. Similar works reported thinner $(\sim 1 \mathrm{~mm})$ PI composite foams with CNTs or with carbon black for the same EMI shielding applications $[12,13]$. Although PI is an insulating polymer and a poor electrical conductor compared to polymers like polyaniline, EMI shielding materials made with PI nano-carbon composites have performed reasonably well in electromagnetic wave absorption [14-16]. Latest advances also led to the fabrication of PI foam aerogels $[17,18]$. They were mainly developed for super-elasticity at deep cryogenic temperatures for aerospace applications. They were reported to be scalable and low-cost [19]. Additional reports and studies demonstrated effective methods to improve acoustic property of PI foams by regulating cellular 
structures on a large scale by introducing sharp hole or pore structure in the cells, achieving a constant sound absorption coefficient of 0.9 from 900 to $6300 \mathrm{~Hz}$ range [20].

Foams (mostly metal and polyurethane) are considered to be good scaffolds to encapsulate phase change materials (PCMs) in order to prevent leakage and the resultant drop in latent heat [21]. Shape stability of PCMs is a very important technological problem. Certain carbon nanomaterials and expanded graphite can improve shape stability of PCMs significantly [22] but also allow their scale up to real applications [23]. The use of PCMs in laminated composite structures has also made some advances recently [24]. Based on the recent review articles on PCM technologies, it can be argued that the development of form-stable, environmentally friendly organic PCMs modified with certain nanomaterials for increased thermal conductivity and structural stability is gaining high popularity among researchers [25-27]. Recent studies have found that combining metals with PCMs can significantly enhance heat storage performance due to much higher heat transfer coefficient of metals causing efficient heat transport. For this reason, metal foam-PCM composites have been proposed [28, 29]. Metal foams tend to shorten the melting time of PCMs such as paraffins [30]. Ceramic foams have also been suggested to encapsulate various PCMs [31-33]. For instance, porous $\mathrm{Al}_{2} \mathrm{O}_{3}$ ceramic foam was compounded with expanded graphite (EG) by calcination method to obtain a foam composite with hierarchical pores. The specific surface area of this composite ceramic foam was 2.3 times that of EG, which enhanced the thermal conductivity and heat transfer performance of phase change materials (PCMs) [34]. Polymeric foams have several benefits compared to more rigid metal and ceramic foams, such as flexibility and ductility, shape recovery, compressibility, and easier fabrication [35]. In general, porous polymer composites fortified with various nanoscale ceramic and metal particles can be effectively used in several applications ranging from food preservation and packaging [36], robust biomedical materials [37], toughening thermosetting resins [38], and designing multifunctional composites such as antibacterial and electro-conductive polymer nanocomposites [39]. Furthermore, polymer composites containing electro-conducive fillers such as nanocarbon materials and $\mathrm{BN}$ have been shown to be the next-generation materials for electromagnetic interference shielding and electronics, as mentioned earlier [40-44]. More specifically, both BN and $\mathrm{SiC}$ are high thermal conductivity ceramics with attractive semiconducting properties. They can also be synthesized in nanoscale with high aspect ratio having morphology like platelets or fibers [45-47] and can be doped with nanocarbons like graphene to attain high conductivity levels both thermally and electrically $[45,48]$.

In this work, we built monolithic laminate structures having a compressed PI foam core and an aluminum foil support.
The foam was adhered to the aluminum substrate by using a paraffinic PCM film, PPF [49, 50]. Another paraffinic PCMceramic composite film was laid over the foam surface and all the layers were hot-pressed into a paper-like layered composite with latent heat storage capability. We used melt compounding to incorporate micron-sized $\mathrm{SiC}$ and nanoscale $\mathrm{BN}$ particles in the paraffinic PCM to improve its thermal conductivity. Upon hot pressing, the cellular structures of the PI foam collapsed irreversibly resulting in a thinner central layer. This simple and solvent-free process can be used to form stable and lightweight PCM layers or coatings on metallic surfaces and the produced layered composites can be integrated into many different thermal energy storage technologies including large area applications such as energy saving buildings.

\section{Experimental}

\subsection{Materials}

Boron nitride nanopowder (nano-BN, intrinsic thermal conductivity: $70 \mathrm{~W} / \mathrm{m} \mathrm{K}$ ) with $99 \%$ trace metal basis was purchased from Merck KGaA (Germany). According to the manufacturer, the average particle size is $<150 \mathrm{~nm}$ (BET) with a particle density of $2.29 \mathrm{~g} / \mathrm{cm} 3$. Silicon carbide powder ( $\mathrm{SiC}$, intrinsic thermal conductivity: $20 \mathrm{~W} / \mathrm{m} \mathrm{K}$ ) was purchased from Merck KGaA (Germany) with a particle size of about 200 mesh $(\sim 70 \mu \mathrm{m})$. A stretchable paraffinic film (PPF) Parafilm ${ }^{\circledR}$ (PM-996, 130- $\mu$ m film thickness), which is a blend of paraffin waxes (55 wt\%) and polyolefin polymers was purchased from Sigma-Aldrich (USA) with a thermal conductivity of $0.2 \mathrm{Wm}-1 \mathrm{~K}-1$. Commercial PI foams were provided by Euroguarco SpA (Italy). They were 1-cm thick with a density of $6.5 \mathrm{~kg} / \mathrm{m} 3$ and a thermal conductivity of $0.046 \mathrm{~W} / \mathrm{mK}$. Aluminum foils $(5 \mathrm{~cm} \times 5 \mathrm{~cm}, 30 \mu \mathrm{m}$ in thickness) were purchased from McMaster-Carr (USA).

\subsection{Fabrication of the PCM monoliths with PI foam core}

Polyimide foams could be irreversibly compressed; unlike for instance melamine foams, they do not resist compression. We compressed the polyimide foams using a hydraulic press at ambient temperature applying $5 \mathrm{mt}$ for $180 \mathrm{~s}$ to induce an irreversible morphology change. In parallel, the paraffinic film (PPF) was compounded with BN nanopowder and $\mathrm{SiC}$ powders using melt compounding and successive hot-pressing [51]. The produced PCM composites had the following material contents. PPF/BN with $30 \mathrm{wt} \%$ and 60 wt $\%$ BN concentration and PPF/SiC with $30 \mathrm{wt} \%$ and 60 wt $\% \mathrm{SiC}$ concentration. Hybrid PCM composites were also fabricated as PPF/BN-SiC in which $\mathrm{BN}: \mathrm{SiC}$ ratio was kept 
Table 1 PCM monoliths studied with different nano-BN/SiC ratios

\begin{tabular}{lllll}
\hline PCM monolith & $\begin{array}{l}\text { BN } \\
(\mathbf{w t} \%)\end{array}$ & $\begin{array}{l}\text { SiC } \\
(\mathbf{w t} \%)\end{array}$ & nano-BN:SiC & Comments \\
\hline PPF & 0 & 0 & $0: 0$ & No fillers \\
PB30 & 30 & 0 & $1: 0$ & BN only \\
PB60 & 60 & 0 & $1: 0$ & BN only \\
PS30 & 0 & 30 & $0: 1$ & SiC only \\
PS60 & 0 & 60 & $0: 1$ & SiC only \\
PH30 & 15 & 15 & $1: 1$ & BN/SiC \\
PH60 & 15 & 30 & $1: 1$ & BN/SiC \\
\hline
\end{tabular}

constant at 1:1. Hybrid PCM nanocomposites contained 30 $\mathrm{wt} \%$ and $60 \mathrm{wt} \%$ total fillers. Sample labeling and concentration details are given in Table 1 . Note that the typical composite contains two layers of PPF film (see Fig. 1) each with $55 \mathrm{wt} \%$ wax content. In total, the composite (including the aluminum substrate) contains about $20 \mathrm{wt} \%$ paraffin wax.

The monolithic composites were fabricated by a simple lay-up and hot pressing process. The bottom aluminum foil layer was covered with the PPF. Over this film, the compressed PI foam was placed and over the PI foam various PCM composite films shown in Table 1 were placed. The final sandwich structure was hot pressed at $65{ }^{\circ} \mathrm{C}$ for 1 min under $1 \mathrm{mt}$ using a hydraulic press (Carver 4386 , Carver Inc., USA). The final monolith thickness was about $\sim 500 \mu \mathrm{m}$. As a result, the composite PCM top layer was embedded in the PI foam. The schematic description of various steps for the fabrication of PCM monoliths is shown in Fig. 1.

\subsection{Electron microscopy}

A scanning electron microscope (SEM JSM-6490LA series, JEOL, Japan) operating with $10 \mathrm{kV}$ of acceleration voltage at different magnifications was used to inspect PCM-composite microstructures and the crosssection morphology of the compressed monoliths. Crosssectioning was carried out by fracturing specimens using cryogenic liquid nitrogen, followed by sputter-coating the fractured surface by $10-\mathrm{nm}$-gold layer.
Fig. 1 Schematic of the PCM monolith assembly. After compression, individual polyimide (PI) cells collapse and the foam structure densifies. Lower Parafilm ${ }^{\circledR}$ layer also ensures an excellent adhesion between the aluminum foil and the compressed foam

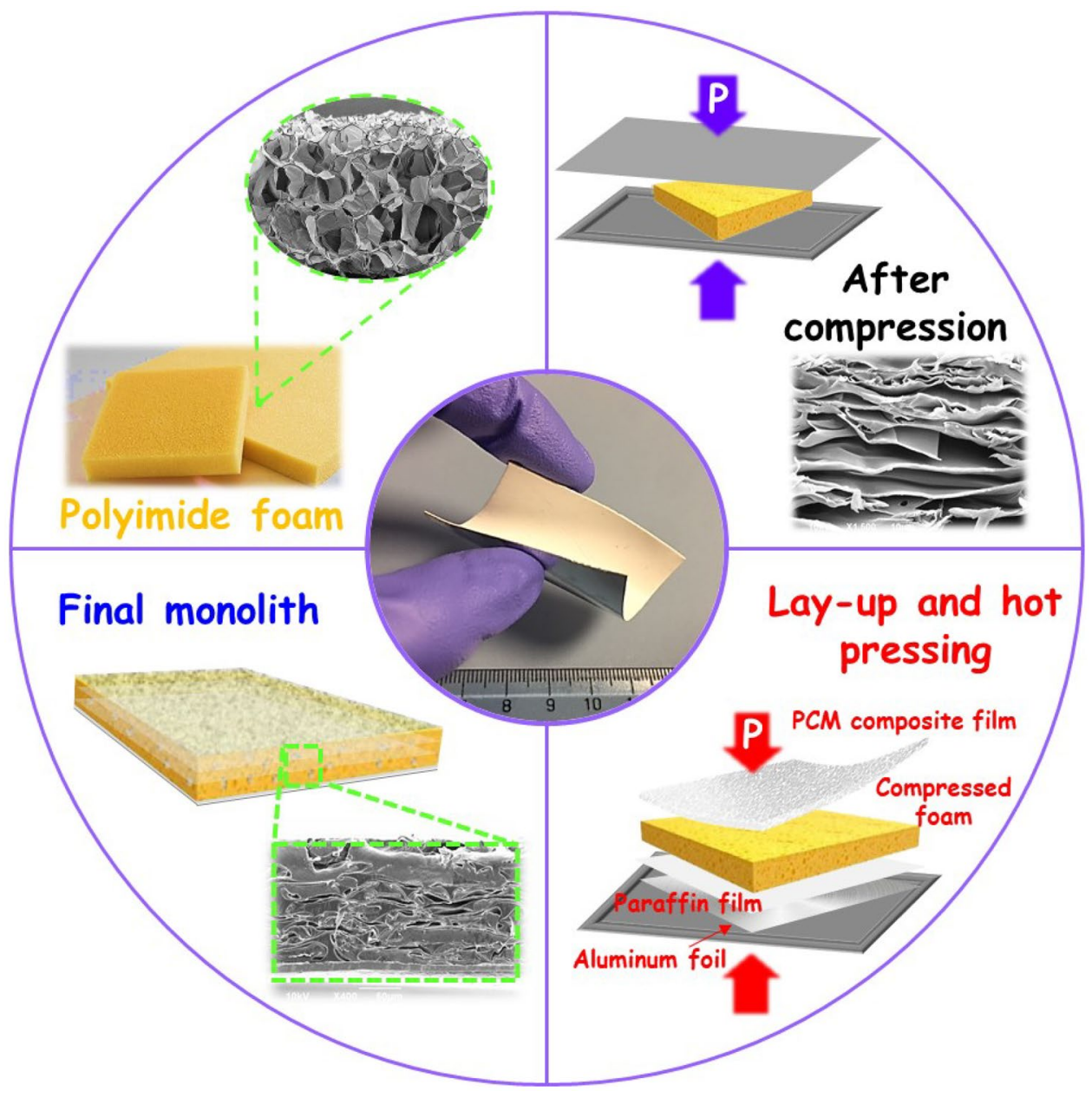




\subsection{FTIR and TGA}

Fourier transform infrared spectroscopy (FTIR) spectrum of the polyimide foam were acquired by using a single-reflection ATR accessory (MIRacle ATR, Pike Technologies) coupled to an FTIR spectrometer (Equinox 70 FT-IR, Bruker). All the spectra were recorded in the range from 2600 to $600 \mathrm{~cm}^{-1}$ with a resolution of $4 \mathrm{~cm}^{-1}$ while collecting 128 scans. The thermal degradation behavior of the polyimide foam was investigated by a standard thermo-gravimetric analysis (TGA) method using a TGA Q500 from TA Instruments (New Castle, DE, USA). Measurements were performed using $\sim 3 \mathrm{mg}$ of sample placed in an aluminum pan under $\mathrm{N}_{2}$ gas. Similar measurements were also made in air with a gas flow rate of $50 \mathrm{~mL} / \mathrm{min}$ covering a temperature range of 30 to $800{ }^{\circ} \mathrm{C}$ with a heating rate of $10^{\circ} \mathrm{C} / \mathrm{min}$. Sample weight loss curve and its first derivative were recorded simultaneously as a function of time and temperature.

\subsection{Mechanical measurements}

The compression tests were performed on polyimide foams using an Instron dual column tabletop universal testing System (3365 Instron, USA) instrument. Cubic foam samples of $1 \mathrm{~cm}^{3}$ were placed between two compressive metal plates in the testing instrument. Compression has been used for characterizing the stress-strain curves behavior of the foams. Load was applied with a trapezoidal routine, with a loading rate of $1 \mathrm{~mm} / \mathrm{s}$ and a dwell time at a maximum load of $60 \mathrm{~s}$. Stress-strain properties of the samples were measured with the same instrument according to ISO 527-2 test method for determination of tensile properties for plastics. Dog boneshaped specimens of $25 \pm 1 \mathrm{~mm}$ in length and $4.0 \pm 0.1 \mathrm{~mm}$ in width were cut by a mechanical cutter and the samples were held by pneumatic clamps in the testing instrument. All the samples were stretched at a constant strain rate of $10 \mathrm{~mm} / \mathrm{min}$. Stress-strain curves were recorded and from the curves, Young's (elastic) modulus in MPa and elongation at break (\%) values were extracted by the built-in instrument software. A minimum of six specimens were tested for each system studied.

\subsection{Wetting measurements}

DataPhysics OCA 20 analyzer (DataPhysics Instruments, Germany) was used to measure the static water contact angles (WCAs) using the sessile drop method. Water droplets were dispensed using a Hamilton syringe with a $0.5-$ $\mathrm{mL}$ volume. Values of the water contact angles were determined by curve fitting with the Young-Laplace equation using the built-in DataPhysics software of the instrument.
A minimum of 10 drops (volume of $5 \mu \mathrm{L}$ and dosing rate of $1 \mu \mathrm{L} / \mathrm{s}$ ) on different spots of the PCM surface were analyzed, and average values were reported.

\subsection{Thermal conductivity and latent heat measurements}

Thermal conductivity measurements of the nanocomposite coatings were carried out using C-Therm TCi Thermal Analyzer Device (C-Therm Technologies Ltd.). Modified transient plane source (MTPS) technique that conforms to ASTM D7984 standard was applied to characterize the thermal conductivity $k$ and effusivity $\varepsilon$ of the fabricated PCM monoliths by applying a heat source from the sensor to the monoliths. Samples, from the composite top layer side, were placed on a circular interfacial heat reflectance sensor (diameter of $2 \mathrm{~cm}$ ) surrounded by a guarded ring. Three drops of deionized water were used as contact agent and deposited at sensor-PCM top layer interface to reduce contact resistance, as per manufacturer specifications. An insulator block was placed on the PCM and then on the top a weight of $500 \mathrm{~g}$ was positioned to ensure full contact between sample and the sensor. Thermal measurements were collected under the same ambient conditions ( T $\sim 21^{\circ} \mathrm{C}$ ). Thermal diffusivity of the PCM monoliths $\alpha$ was calculated as $\alpha=k / \varepsilon$. PCMs with a top layer made with unfilled pure PF were also measured as control sample. A minimum of 20 measurements were performed for each PCM tested.

The latent heat storage characteristics of different samples and monoliths were monitored by heating them on a hot plate at $75^{\circ} \mathrm{C}$ and then quickly transferring them on a smooth metal surface in the vicinity of the heater maintained at $10{ }^{\circ} \mathrm{C}$. The cooling dynamics of each sample was recorded using an infrared camera (IR camera) FLIR A655sc model. Although the surface temperature of the samples analyzed was homogeneous, the software of the infrared camera allowed calculation of average temperatures of selected areas over the surfaces. Therefore, instead of recording local temperatures over the surface, area-averaged temperatures on each sample were recorded and analyzed.

Differential scanning calorimetry (DSC) curves were obtained by using a Diamond DSC-Perkin Elmer instrument from 0 to $130{ }^{\circ} \mathrm{C}$ under dry nitrogen flow at a heating rate of $10{ }^{\circ} \mathrm{C} / \mathrm{min}$. Accurately weighed samples were placed in an aluminum pan and a programmed heating-cooling-heating cycle was recorded. The glass transition $\left(T_{\mathrm{g}}\right)$ and melting temperatures $\left(T_{\mathrm{m}}\right)$ of the composite PCM top layers were calculated from the plots. In order to compare the results obtained, we also measured the DSC curve behavior of the pure PF (Parafilm). Enthalypy of melting values $\left(\Delta H_{\mathrm{m}}\right.$ in $\mathrm{J} / \mathrm{g}$ ) were also caculated by the built-in software of DSC. 


\subsection{Porosity measurements}

Mercury intrusion porosimetry was used to characterize the pore structures of the original and compressed PI foams. Porosity in general refers to all pores (open and closed). Mercury intrusion porosimetry can only measure the percentage of open pores that are mercury accessible. Experiments were carried out with both low pressure and high pressure (P.A.S.C.A.L, POROTEC, Germany) porosimeters for measuring macro and submicron pores. Small isomorph samples were used to avoid the effect of uncut pores and to eliminate anisotropic effects that may result from the cutting direction. Samples of about $0.3 \mathrm{~g}$ were cut that are about $3 \mathrm{~mm}$ on each side. They were kept in a desiccator for $2 \mathrm{~h}$ to ensure drying of the samples. Then the measurements were conducted by increasing the pressure up to $400 \mathrm{MPa}$ over the samples immersed in the non-wetting mercury. If the pressure is increased in a controlled manner, at lower pressure levels, the mercury will penetrate into larger pores and upon further increase in pressure, the mercury will penetrate into progressively smaller voids. The pore volume can be derived from the quantity of intruded mercury. The pore size distribution can be determined according to the Washburn equation assuming the foam is a porous material comprising a bundle of small cylindrical capillaries [52].

\section{Results and discussions}

Before constructing the sandwich structures, we investigated the changes in the cellular microstructure of the PI foam before and after compression. Figure $2 \mathrm{a}$ and $\mathrm{b}$ show the results acquired from the compression test and the crosssection SEM images, at different magnifications, of the foam before (Fig. 2c, d) and after pressing/compression (Fig. 2c, d). Preliminarily, we applied a compressive load with a trapezoidal distribution (Fig. 2a) on three different PI foams to test their energy absorption and recovery capabilities. From the analysis of the compression dynamics, we detect three regimes in Fig. 2b. The first one is an initial phase of linear elasticity with a very low modulus that seems to extend beyond $20 \%$ strain, and then a quasi-plateau region up to about $60 \%$ where the foam is able to resist the applied compressive load. In this region, formation of a larger deformation effect and initiation of elastic cellular buckling can be seen in Fig. 2b. Finally, beyond 60\% strain, a region with high modulus response starts in which a sharp increase in compressive stress with practically no further deformation occurs indicating that the cellular structure is compressed onto itself. As a result, the cellular structure densifies and the pores collapse $[53,54]$. From the data in Fig. $2 b$, it is noted that the PI foam exhibits no shape recovery after the load is released and as such, the shape deformation remained irreversible.

Comparing microscopic features in Fig. 2c and d with $\mathrm{e}$ and $\mathrm{f}$, the changes in the cellular structure can be clearly observed. The collapsed PI foam after $~ 96 \%$ strain compression shows a layered structure still preserving a good degree of porosity as the magnified SEM image shows in Fig. 2f.

Figure 3 shows estimated pore size distribution of the PI foam before and after compression in terms of percent relative volume and specific volume as a function of pore diameter. The pore diameter distribution of the PI foam shows a major clustering around $100-500 \mu \mathrm{m}$ range with the presence of very few smaller pores larger than $100 \mathrm{~nm}$. Upon compression, the pore size distribution is modified but still demonstrates a major size distribution cluster around the same range with a slight shift toward higher pore sizes. Upon compression, an increase in sub-microscopic pore sizes could also be noticed in Fig. 3. This is attributed to the fact that upon compression no cell is completely closed but only the cell geometry changes due to the collapse of the cell walls under compression.

Similarly, the specific volume of both foams declined significantly at large pore diameters $(>100 \mu \mathrm{m})$ and below this threshold, due to compression, the specific pore volume of the compressed foam was about $20 \%$ higher than the PI foam before compression due to cell wall collapse. Based on the same mercury intrusion porosimetry analysis, the density of the compressed foam was measured to be $0.1756 \pm 0.0005 \mathrm{~g} /$ $\mathrm{cm} 3$, while for the PI foam (before compression) the bulk density was measured to be $0.00743 \pm 0.0002 \mathrm{~g} / \mathrm{cm} 3$ that is close to the manufacturer specification of $6.5 \mathrm{~kg} / \mathrm{m} 3$. The SEM images in Fig. 2 appear to confirm the porosity size measurements and the compression process only causes more elongated cells rather than closure of the actual pores $[13,54]$. The polyimide foam was also characterized by attenuated total reflection Fourier transform infrared (ATRFTIR) spectroscopy. Figure 4a shows the ATR-FTIR spectra of the as received PI foam. Main characteristic peaks that were assigned to the foam are reported in Fig. $4 \mathrm{~b}$. The characteristic absorption bands appeared at 1778 and $1718 \mathrm{~cm}-1$ (asymmetric and symmetric $\mathrm{C}=\mathrm{O}$ stretching modes respectively) and at $1365 \mathrm{~cm}-1$ (C-N stretching).

From the spectrum, we also observed the characteristic band at $1207 \mathrm{~cm}-1$ that can be attributed to tertiary amine $\mathrm{C}-\mathrm{N}$ stretching as well as aromatic $\mathrm{C}-\mathrm{H}$ in plane bands [55], and the bending vibration of the $\mathrm{C}=\mathrm{O}$ appears at $720 \mathrm{~cm}-1$. Thermal degradation characteristics of the PI foam were evaluated in nitrogen (N2) and in air by thermogravimetric analysis (TGA), and the results are summarized in Fig. 4c and $\mathrm{d}$. As seen under $\mathrm{N} 2$ gas, the foam shows better thermal stability all the way up to $800{ }^{\circ} \mathrm{C}$. The main weight loss starts at around $550{ }^{\circ} \mathrm{C}$, and at the end of $800{ }^{\circ} \mathrm{C}$, about $40 \%$ weight loss took place. On the contrary, under ambient 
a)
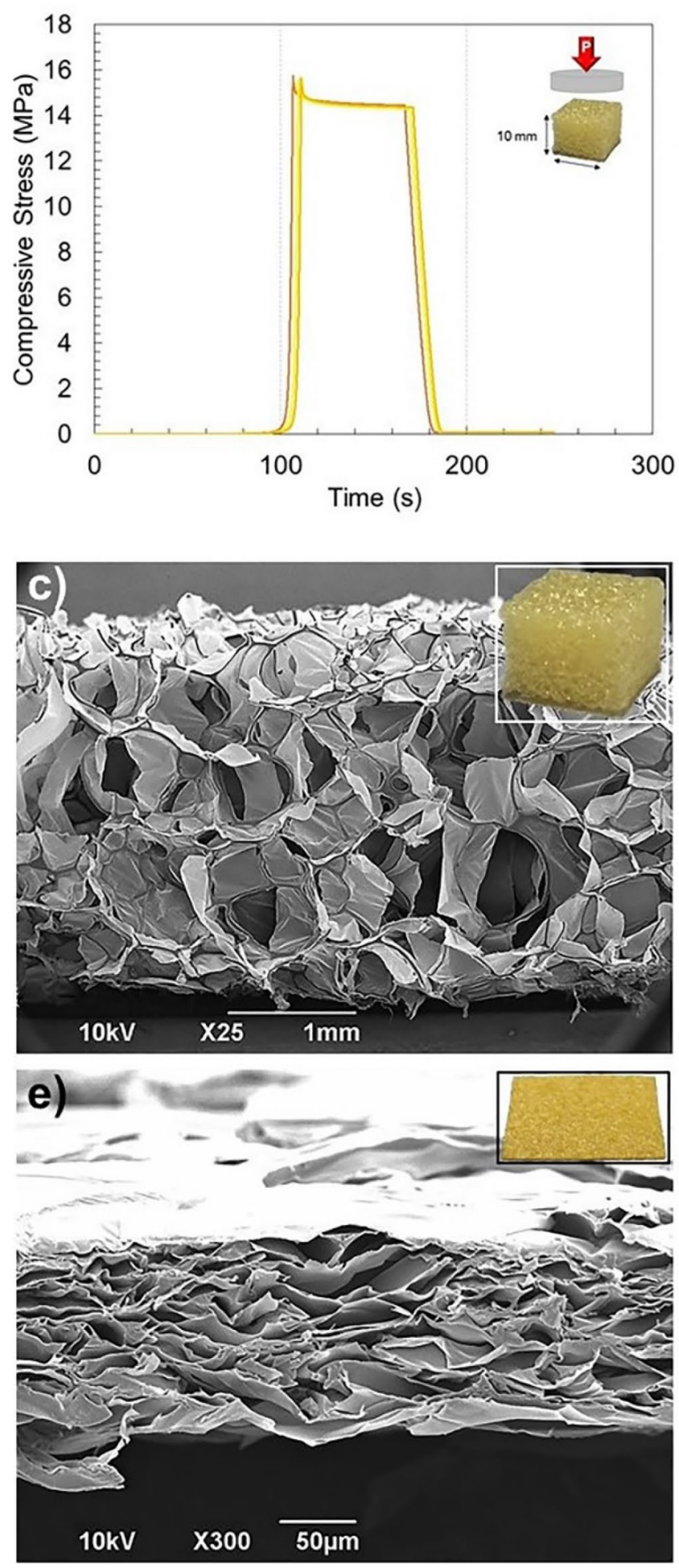

Fig. 2 a) Compression test with a trapezoidal force profile and stresstime response and b) with a) stress-strain response from three different cubic PI foam samples. c) Cross-section SEM image of the PI foam, d) with higher magnification. e) SEM image of the compressed b)
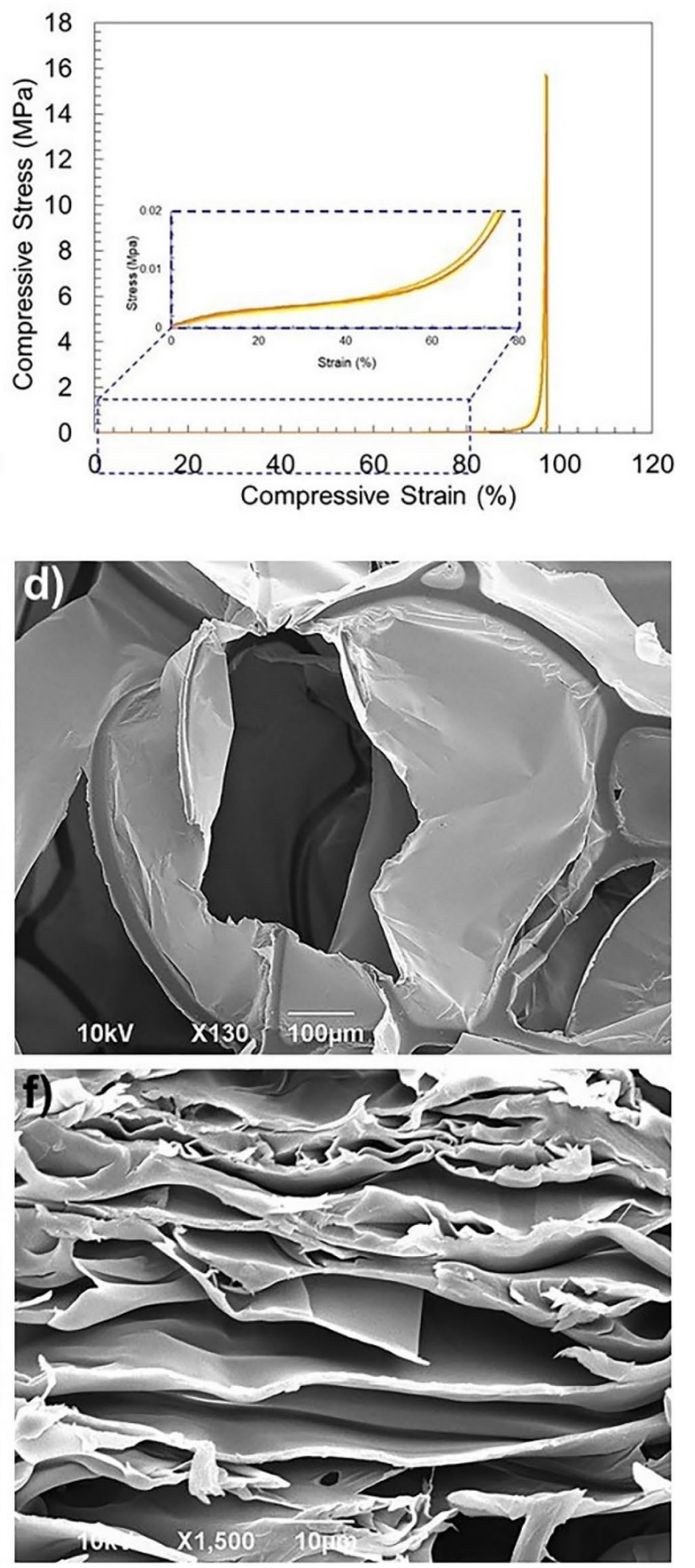

foam and f) magnified SEM image of the same foam. Insets in c) and e) are the photographs of the foam before and after compression, respectively 
Fig. 3 Percent pore volume and specific volume changes as a function of pore diameter for the PI foam before and after compression. All the measurements were within $\pm 5 \%$ uncertainty

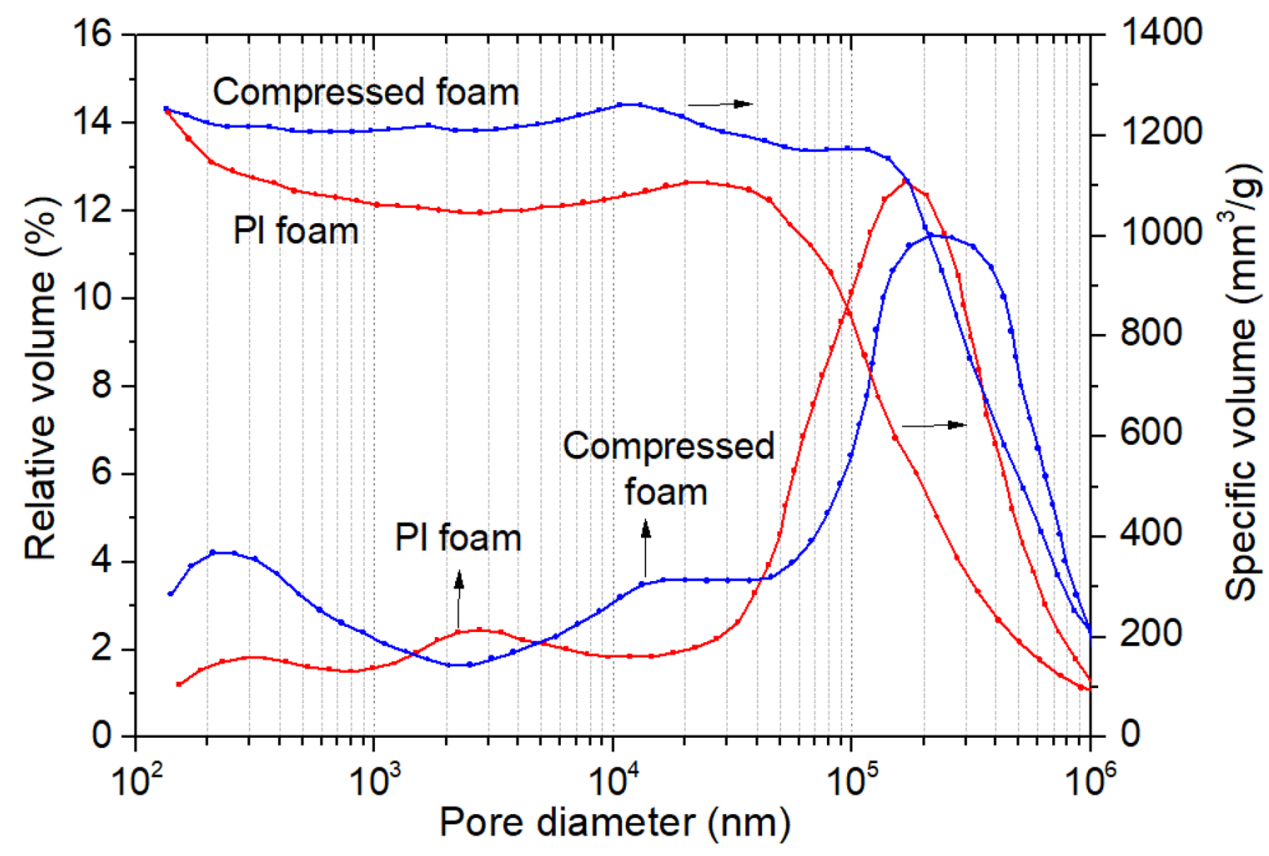

air, mass loss starts at about $400{ }^{\circ} \mathrm{C}$ and about $15 \%$ weight loss was registered at around $500{ }^{\circ} \mathrm{C}$. After about $575^{\circ} \mathrm{C}$, a sudden mass loss occurred and practically no solid residues remained (Fig. 4c). Inspecting the derivative of the weight loss curve in Fig. 4d, under N2 gas, a non-zero derivative curve appears at about $400{ }^{\circ} \mathrm{C}$ indicating that a small amount of degradation under non-oxidizing conditions occurs, probably in the form of solid to gas transformation of certain monomeric segments. The other weight loss occurs at around $575^{\circ} \mathrm{C}$, under non-oxidizing condition, but the peak is much smaller in strength. In air, the massive weight loss clearly peaks at around $575^{\circ} \mathrm{C}$, according to Fig. $4 \mathrm{~d}$.

\subsection{Morphological analysis of the PCM monoliths}

Before investigating the morphological features of the monoliths, Fig. 5a and b show typical SEM images of the nano-BN and $\mathrm{SiC}$ micro-powder morphologies. Both powders do not feature a uniform particle size dispersion, and the analysis of similar SEM images confirmed the average particle size values provided by the manufacturers (reported in "Sect. 2.1"). Additionally, Fig. 5c and d show the photographs of a PCM composite that contain $60 \mathrm{wt} \%$ nano-BN powder (sample PB60) that is used as the top layer. Figure $6 \mathrm{a}$ shows an illustration of the lay-up process for the composite fabrication. Figure $6 \mathrm{~b}$ shows the compressed foam sandwiched between two unfilled PF (Parafilm®) films (crosssection SEM of the sample PPF). The lower PF layer also ensures adhesion to the Al foil surface. Figure $6 \mathrm{c}$ shows a similar sandwich structure in which the compressed foam is pressed between PB60 top layer and unfilled PF lower layer. In both cases, firm monolithic structures could be fabricated.
The presence of nano-BN in the top layer enhances impregnation of both layers into the core foam (Fig. 6c), justifying the use of thermally conducting fillers in the waxy phase change material. Similarly nano-BN/SiC composite PCMs showed satisfactory results in terms of impregnation into the foam structure.

As the foam is pressed and collapsed, the cell walls turn into a sheet-like structure (see Fig. 2). However, as the waxes and the particles penetrate into this texture during pressing, the morphology transforms into a hybrid sheet-like and porous morphology as seen in Fig. 6c. Not all the pores are filled during this process and hence such cross-section structures form.

\subsection{Mechanical properties of the PCM monoliths}

Figure 7 summarizes the mechanical properties of the composite PCM top layers (not the monoliths). Films containing 30 and $60 \mathrm{wt} \% \mathrm{BN}$ and $\mathrm{SiC}$ fillers were labeled as BN 30 wt $\%, \mathrm{BN} 60 \mathrm{wt} \%$, SiC $30 \mathrm{wt} \%$, and $60 \mathrm{wt} \%$, respectively. Those containing 1:1 fillers having the same concentrations were labeled as Hybrid $30 \mathrm{wt} \%$ and Hybrid $60 \mathrm{wt} \%$, respectively. In order to compare the obtained results, we also reported the stress-strain behaviors of the pure PF, the aluminum foil, and the compressed PI foam. The compressed PI foam does not have any elastic or stretching properties just like the aluminum foil as seen in Fig. 7a. More specifically, the aluminum foil and the PI compressed foam showed Young's (elastic, E) moduli of $\sim 20 \mathrm{GPa}$ and $\sim 130 \mathrm{MPa}$, respectively. The pure PF stretches to about $\varepsilon \sim 420 \%$ before rupture with an $\mathrm{E}$ value of about $22 \mathrm{MPa}$. Adding $\mathrm{BN}$ nanoparticles partially stiffened the PF, and the composite 


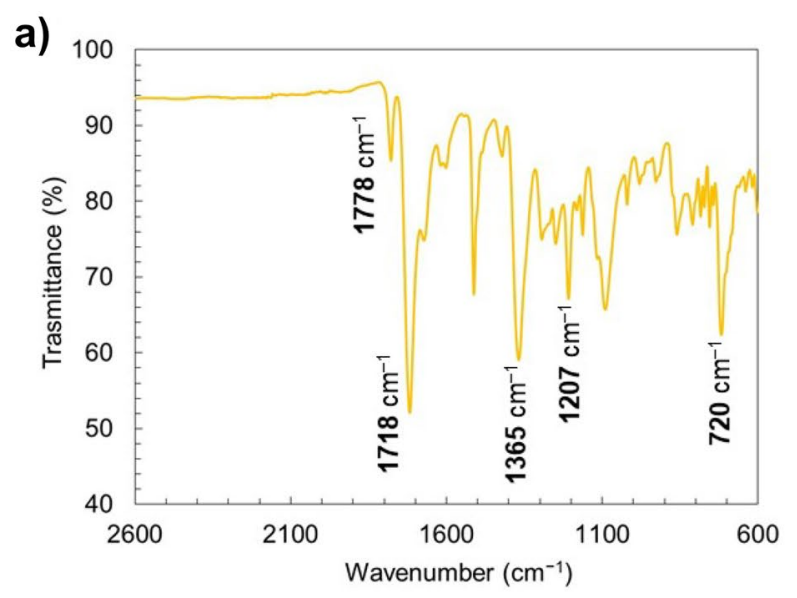

b)

\begin{tabular}{cc}
\hline $\begin{array}{c}\text { Peak } \\
\left(\mathbf{c m}^{-1}\right)\end{array}$ & $\begin{array}{c}\text { Molecular vibrational } \\
\text { mode }\end{array}$ \\
\hline 1778 & Asym. C=O stretch \\
\hline 1718 & Sym. C=O stretch \\
\hline 1365 & C-N stretch \\
\hline 1207 & $\begin{array}{c}\text { Tertiary amine/aromatic } \\
\text { CH stretch }\end{array}$ \\
\hline 720 & C=O bending \\
\hline
\end{tabular}
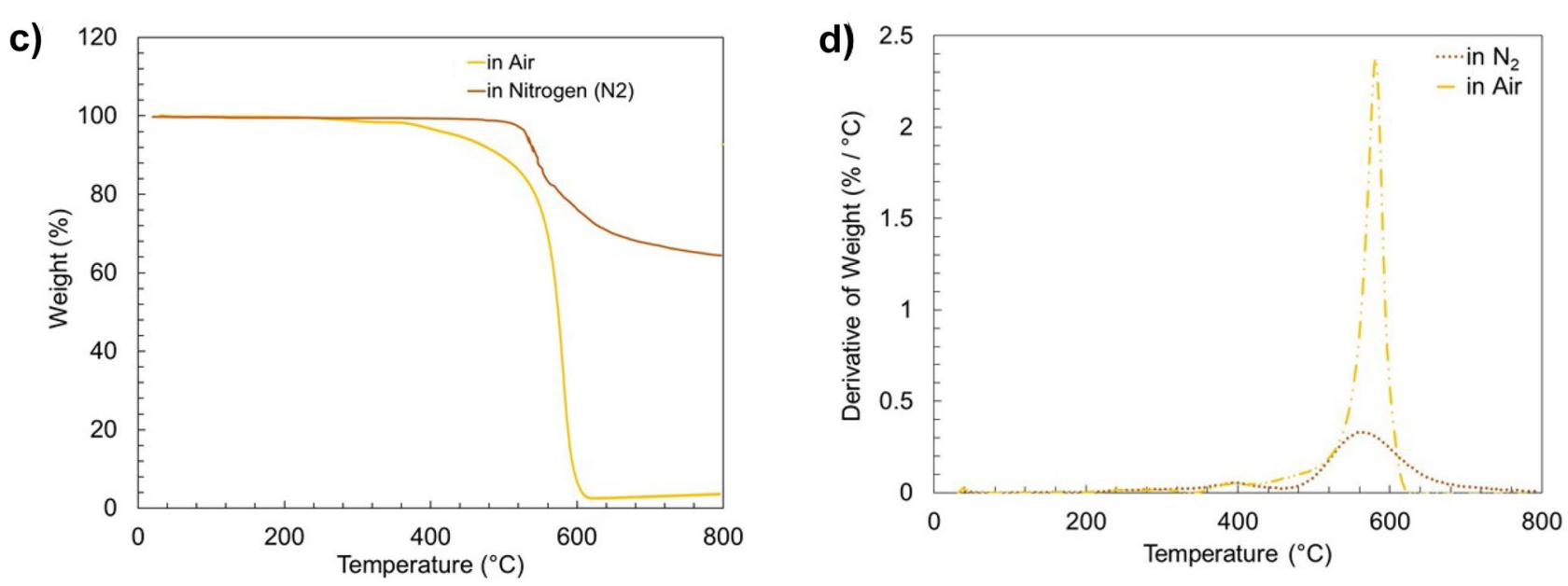

Fig. 4 a) ATR-FTIR spectrum of polyimide foam and b) the corresponding molecular vibration modes identified. c) Thermal degradation (TGA) curves of the PI foam in air and in nitrogen. d) The derivative of the degradation curves is shown in c)
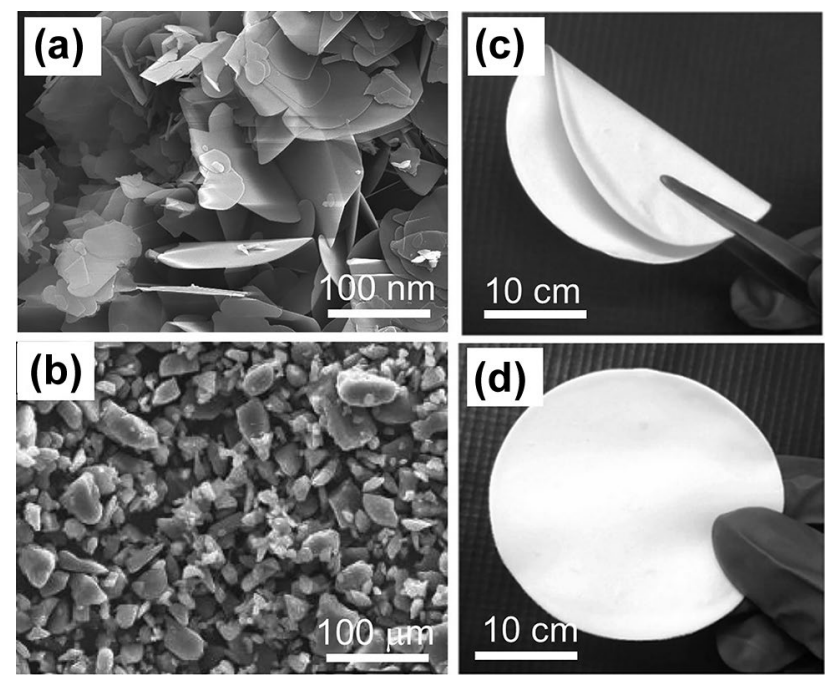

Fig. 5 (a) SEM image of the submicron BN powder used in the PCM composites. (b) SEM image of the SiC micro-particles. Photographs in (c) and (d) show the Parafilm ${ }^{\circledR}$ compounded with $60 \mathrm{wt} \% \mathrm{BN}$ powder using melt blending demonstrated lower strain before break values, as summarized in Fig. 7b.

Surprisingly, compounding micron scale SiC particles into the PF, strain before break values increased, in other words, the composites were more ductile than the $\mathrm{BN}$ composites. The elongation before break values exceeded even pure PF. In the case of composites containing either nano-BN or SiC fillers, the composite PCBs could retain a higher stress value at a given strain level before break. The improvement in ductility due to $\mathrm{SiC}$ particles can be attributed to a phenomenon known as particle-reinforced plasticity in connection to re-dispersion of the wax that acts as a plasticizer within the thermoplastic due to the presence of the particles. The wax can interact with the particles during compounding and can conform to the dispersion patterns of the particle aggregates within the thermoplastic enabling a better plasticization [56, 57].

In fact, careful inspection of the SEM image in Fig. $6 \mathrm{~b}$ shows several wax crystal aggregates in the PF that are no 
a)

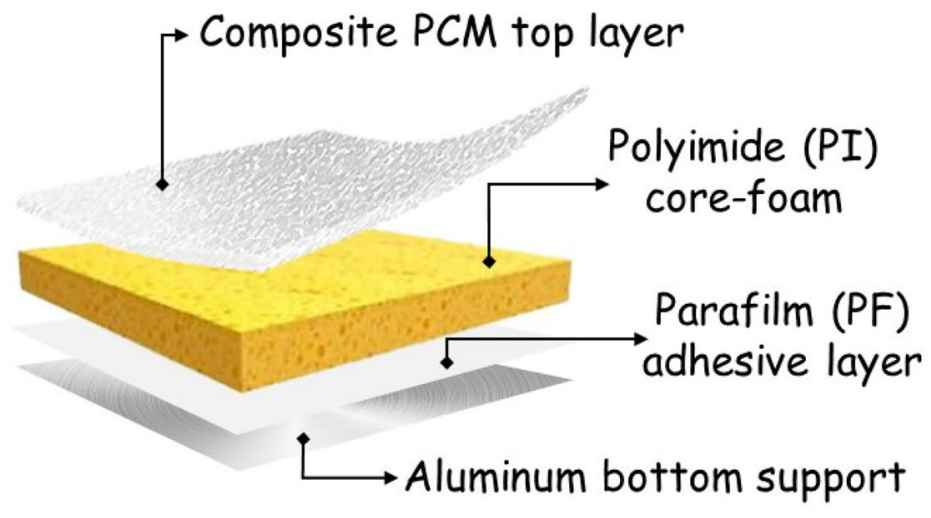

Final monolith

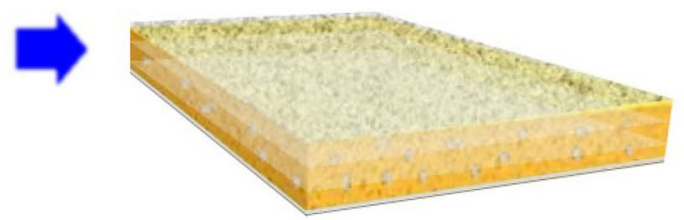

(After hot-press) b)

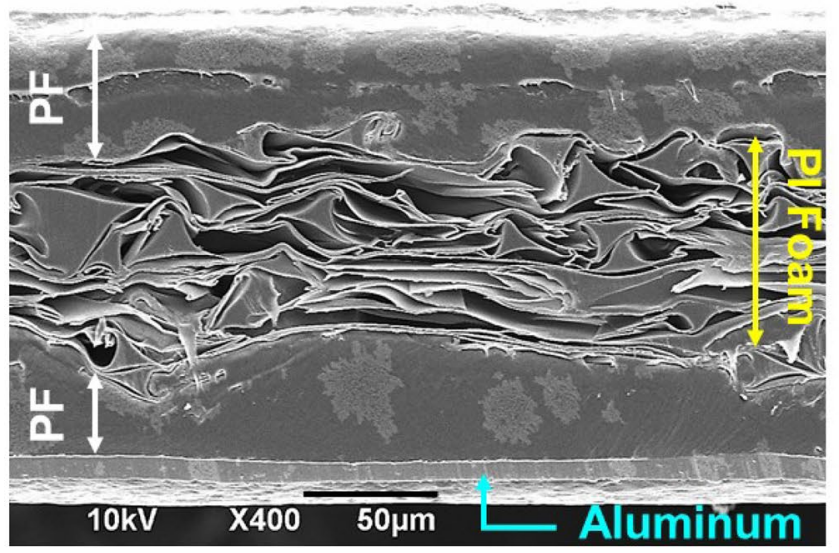

c)

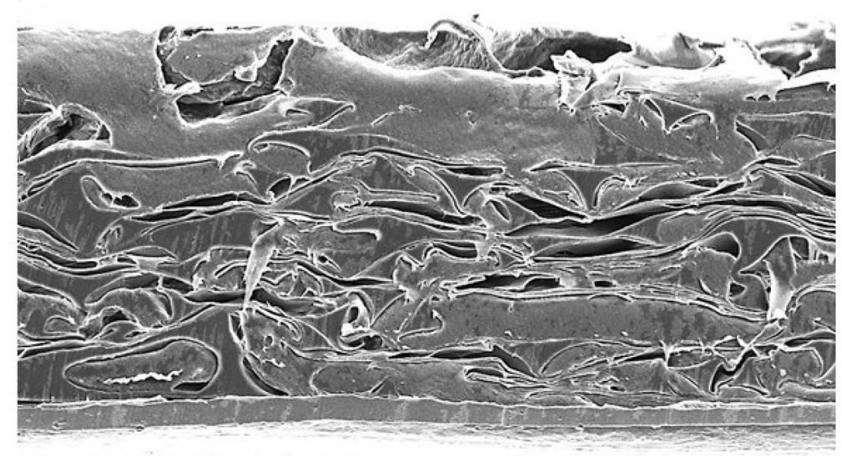

$1 0 \mathrm { kV } \times 4 0 0 \longdiv { 5 0 \mu m }$

Fig. 6 a) Schematic illustration of the sandwich-structured PCM monolith fabrication process. b) Cross-section SEM image of PPF. c) Crosssection SEM image of PB60. For details, see Table 1

a)

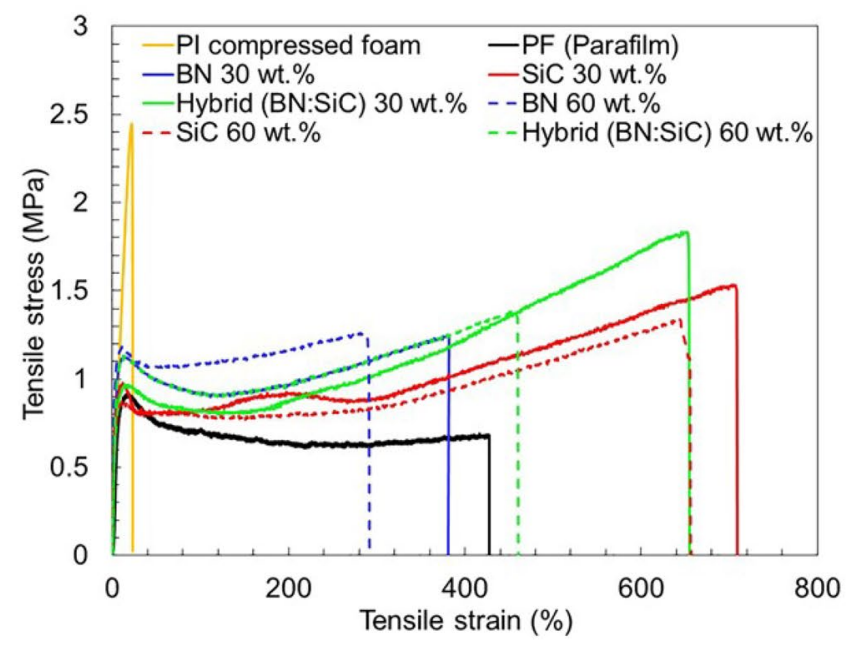

b)

\begin{tabular}{lcc}
\hline PCM top layer & E (MPa) & $\varepsilon(\%)$ \\
\hline PF & $25 \pm 10$ & 430 \\
\hline Al foil & $(20 \pm 15) \times 10^{3}$ & 10 \\
\hline BN 30 wt. $\%$ & $45 \pm 10$ & 380 \\
\hline BN 60 wt. $\%$ & $85 \pm 20$ & 290 \\
\hline SiC 30 wt. $\%$ & $46 \pm 25$ & 710 \\
\hline SiC 60 wt. $\%$ & $60 \pm 15$ & 660 \\
\hline Hybrid 30 wt. $\%$ & $44 \pm 22$ & 650 \\
\hline Hybrid 60 wt. $\%$ & $55 \pm 12$ & 460 \\
\hline
\end{tabular}

Fig. 7 a) Stress-strain curves of all the composite PCM top layers fabricated as well as the PI foam and pure PPF. b) Young's modulus (E) and elongation at break $\varepsilon(\%)$ values extracted for all the samples shown in a) and the $\mathrm{Al}$ foil as well (not shown in a) 
longer apparent in the composite PCBs or the hybrids (see Figure S1). In addition, in the case of the hybrid samples, we measured both increased Young's moduli and elongation at break values compared to the pure PF as shown in Fig. 7b. Analysis of the differential scanning calorimetry (DSC) thermograms reported in the supplementary information (see Figure $\mathrm{S} 2$ and Table $\mathrm{S} 1$ ) yielded that the $\mathrm{SiC} 30$ wt\% PCM composite had the lowest glass transition temperature $\left(\mathrm{Tg} \sim 38.5^{\circ} \mathrm{C}\right)$, confirming its ability to stretch and undergo plastic deformations without undergoing fractures [5]. The fact that we did not observe a similar effect with the nano-BN particles could be attributed to their 2D platelet morphology and a different degree of dispersion of such particles in the same PCB matrix compared to quasi-spherical $\mathrm{SiC}$ particles.

Following this analysis, Fig. 8 shows the tensile properties of the final PCM monoliths fabricated. Photographs in Fig. 8a, show typical sequence of events during stretching and subsequent rupturing of different layers within the monolith PS30. After the application of the first strain (indicated as stage I in Fig. 8), the first failure happens in the lower $\mathrm{Al}$ layer as it fractures (II) and this is followed by the compressed foam breaking (III). The ductile rupture of the PF adhesive layer occurs next (IV) and finally the top PCM composite film breaks (V). In Fig. 8b and c, we reported the stress-strain curves of all PCM monoliths including the PPF control monolith having the PF top layer. Analysis of the results in Fig. 8c indicates that the monolith made with the nano-BN PCB composite top layers have the highest Young's moduli (E) values exceeding $1 \mathrm{GPa}$, whereas the monoliths with $\mathrm{SiC}$ composite PCMs feature elastic moduli close to $1 \mathrm{GPa}$ but with twice the stretching ability. The same argument holds for the monoliths with the hybrid PCM top layers. Hence, we can conclude that by modifying the top PCM layers or films with ceramic fillers, the mechanical properties of the monoliths can be improved significantly.

Hydrophobicity of the PCM monoliths were also investigated as displayed in Table 2. We found that the hydrophobicity of the PF film was not lost upon compounding with nano-BN and SiC fillers. All static contact angles exceeded a)
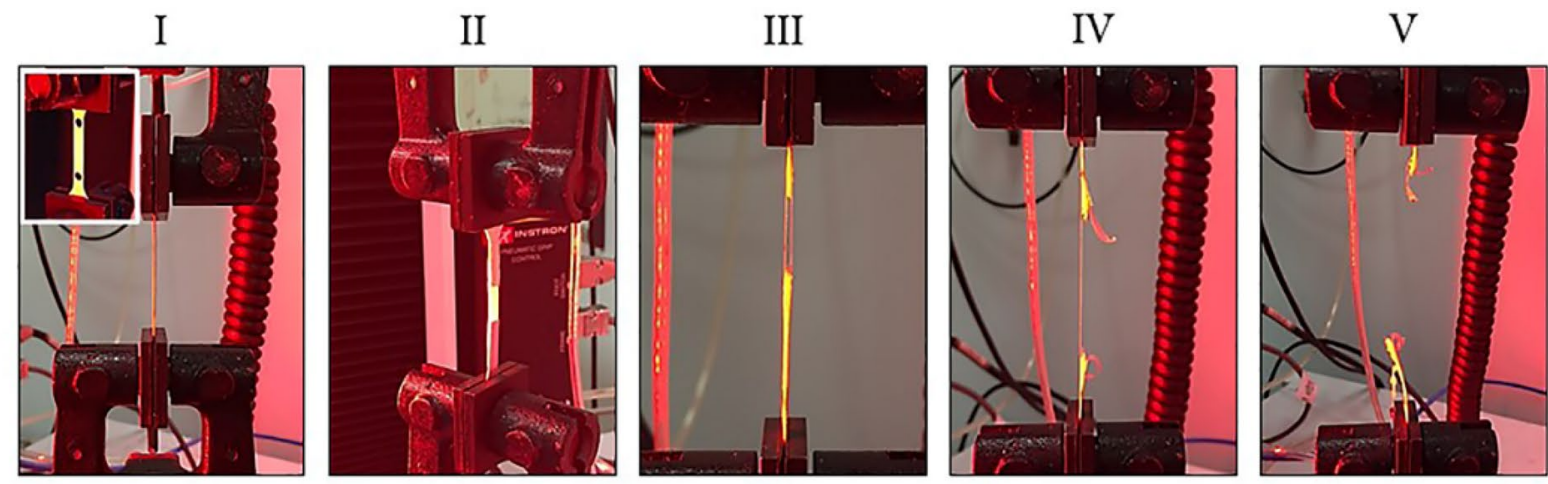

b)

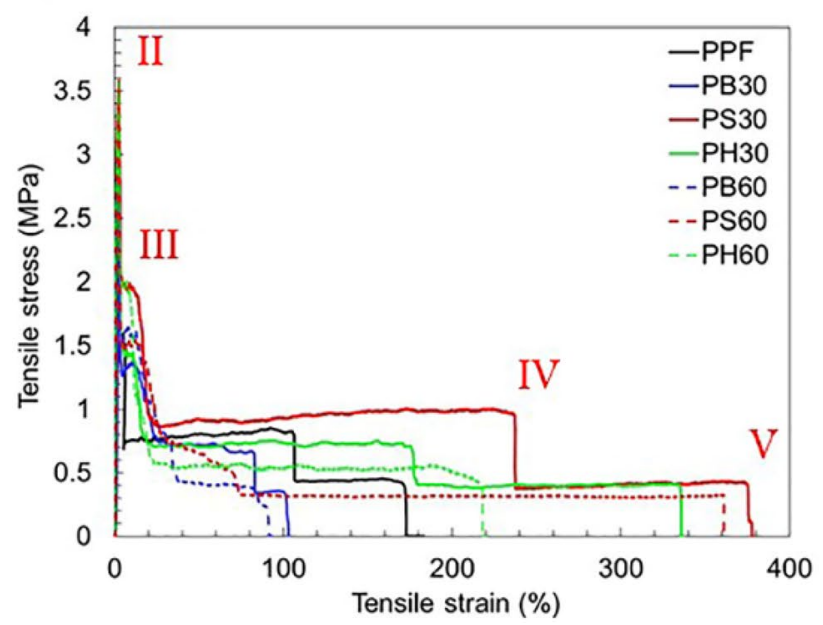

c)

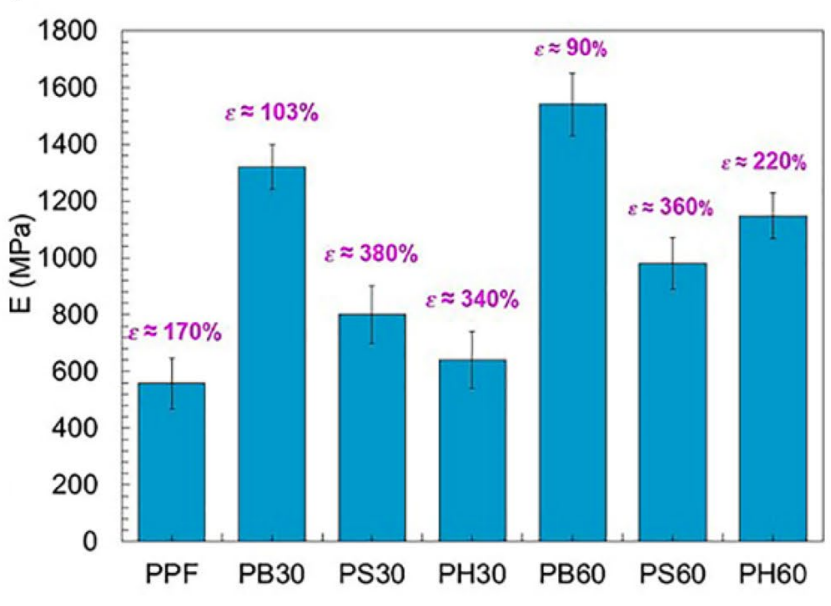

Fig. 8 a) Sequence of photographs showing typical events during strain testing of a monolith and b) stress-strain curves of all the sandwichstructured monoliths studied. c) Calculated Young's moduli, E, and the corresponding elongation at break $\varepsilon(\%)$ values shown in c) 
Table 2 Static water contact angle values (WCAs) and sliding angles for $15-\mu \mathrm{L}$ droplets

\begin{tabular}{lll}
\hline PCM monolith & WCA $\left(^{\circ}\right)$ & $\begin{array}{l}\text { Water sliding } \\
\text { angle }\left({ }^{\circ}\right)\end{array}$ \\
\hline PPF & $100.0 \pm 1.0$ & $25.4 \pm 4.0$ \\
PB30 & $103.4 \pm 1.1$ & $20.2 \pm 3.0$ \\
PB60 & $107.8 \pm 0.9$ & $34.3 \pm 6.0$ \\
PS30 & $106.4 \pm 1.3$ & $15.4 \pm 5.0$ \\
PS60 & $107.6 \pm 1.0$ & $28.3 \pm 4.0$ \\
PH30 & $106.0 \pm 0.8$ & $24.5 \pm 6.0$ \\
PH60 & $108.2 \pm 0.6$ & $32.6 \pm 6.0$ \\
\hline
\end{tabular}

$100^{\circ}$, and droplets could slide on the surfaces of the composite films. Water droplet sliding angles are also reported in Table 2 for $15-\mu \mathrm{L}$ droplets.

\subsection{Thermal properties of the monoliths}

Table 3 shows the through-plane thermal conductivity $\mathrm{k}$ values of all PCM monoliths fabricated in this study. The monolith with no fillers has the lowest thermal conductivity compared to all other monoliths. Similarly, it features the lowest thermal diffusivity $\alpha$ and thermal effusivity $\varepsilon$ values. It is important to note that a designed composite structure with a potential latent heat storage capacity should sense and transport heat quickly within its structure in order to respond to the changes in its environment effectively. As such, thermal diffusivity is an important parameter for the PCMs in general and in this case, the monoliths made with the composite top PCM layers have more than $50 \%$ improvement in the rate of transfer due to their higher diffusivity. Similarly, the thermal effusivity increases within 30-40\% demonstrating improved thermal energy exchange with the surroundings.

To examine the potential latent heat storage capabilities of the monoliths, we conditioned them on a hot surface at around $70{ }^{\circ} \mathrm{C}$ and once the monolith temperature equalized

Table 3 Through-plane thermal conductivity $\mathrm{k}$, diffusivity $\alpha$, and effusivity $\varepsilon$ values obtained for all PCM monoliths

\begin{tabular}{llll}
\hline PCM monolith & $\boldsymbol{k}\left(\mathbf{W m}^{-\mathbf{1}} \mathbf{K}^{\mathbf{- 1}}\right)$ & $\begin{array}{l}\boldsymbol{\alpha} \\
\left(\mathbf{m}^{\mathbf{2}} / \mathbf{s}\right) \times \mathbf{1 0}^{-\mathbf{4}}\end{array}$ & $\boldsymbol{\varepsilon}\left(\mathbf{W s}^{\left.\mathbf{1 / 2} / \mathbf{m}^{\mathbf{2}} \mathbf{K}\right)}\right.$ \\
\hline PPF & $0.18 \pm 0.03$ & 2.6 & 620 \\
PB30 & $0.31 \pm 0.03$ & 4.4 & 706 \\
PB60 & $0.50 \pm 0.04$ & 5.3 & 940 \\
PS30 & $0.47 \pm 0.01$ & 5.4 & 870 \\
PS60 & $0.46 \pm 0.03$ & 5.0 & 920 \\
PH30 & $0.33 \pm 0.01$ & 4.5 & 716 \\
PH60 & $0.47 \pm 0.02$ & 5.0 & 890 \\
\hline
\end{tabular}

with the hot surface, they were transferred to a cold surface at $13-15{ }^{\circ} \mathrm{C}$ in the vicinity, and their cooling dynamics were recorded with an IR camera. Note that pure PF could not be tested by itself due to its melting above $50{ }^{\circ} \mathrm{C}$ and leaching and sticking on the hot surface. If the monoliths store latent heat, they would cool slower than their counterparts that contain no PCMs.

Ideally, a constant temperature zone should appear in the cooling curve corresponding to the solidification phase change of the PCB. As seen in Fig. 9a, compressed PI foam has the fastest temperature drop curve and within $20 \mathrm{~s}$, its temperature cools down to $13{ }^{\circ} \mathrm{C}$. Contrarily, PS30 monolith has the slowest cooling rate. At $20 \mathrm{~s}$, its temperature is at $34{ }^{\circ} \mathrm{C}$ compared to the compressed foam itself. This significantly justifies the use of the sandwich structure. The sample PPF is the monolith with no fillers. It performs better than the compressed PI foam but it remains at a lower temperature of $22{ }^{\circ} \mathrm{C}$ compared to PS30. The second best performance was obtained from PB60 monolith in which its temperature after $20 \mathrm{~s}$ of cooling was recorded to be $27^{\circ} \mathrm{C}$. In both monoliths (PS30 and PB60), a phase change zone was detected. In the case of PS30, this was located between 7 and $10 \mathrm{~s}$, and for PB60 it took place between 5 and $10 \mathrm{~s}$. Hybrid samples PH30 and PH60 followed identical (overlapped) temperature profiles that were similar and close to PPF monolith curve. Note that at the end of $40 \mathrm{~s}$, PS30 still outperforms other monoliths including the PPF monolith with no ceramic fillers.

Specifically, looking at the slope of the cooling profiles in Fig. 9b that is known as the cooling rate (dT/dt), in the first $10 \mathrm{~s}$, PS30 monolith showed lower cooling rates and the calculated cooling rates after this period did not diminish to zero levels but remained positive indicating good heat storage potential of this particular monolith. Cooling rate of the PB60 also followed a similar trend and continued to cool further down. Typical infrared images exemplified in Fig. 9c also demonstrate that PS30 remains warmer at $30 \mathrm{~s}$.

The difference in the cooling performance between PS30 and PB60 may be explained by looking at their microscale morphology. It is very difficult to maintain a high quality of dispersion in composites containing 2D nanoscale fillers like BN at high concentrations. This can cause formation of unwanted agglomerates and porous morphology. The SEM images shown in Figure S1 (Supplementary Information) appear to support this argument. Therein, for instance, the cross-section SEM image of PS30 and PB60 top layers (not the full monolith cross-sections) are displayed, and PS30 appears to much less porous compared to PB60. The inherent porosity of the top layer film might reduce the heat transport effectiveness and diminish the cooling performance at $60 \mathrm{wt} \%$ nano-BN loading. Additionally, Figure S2 shows the DSC curves of all the top layer composite films. DSC 

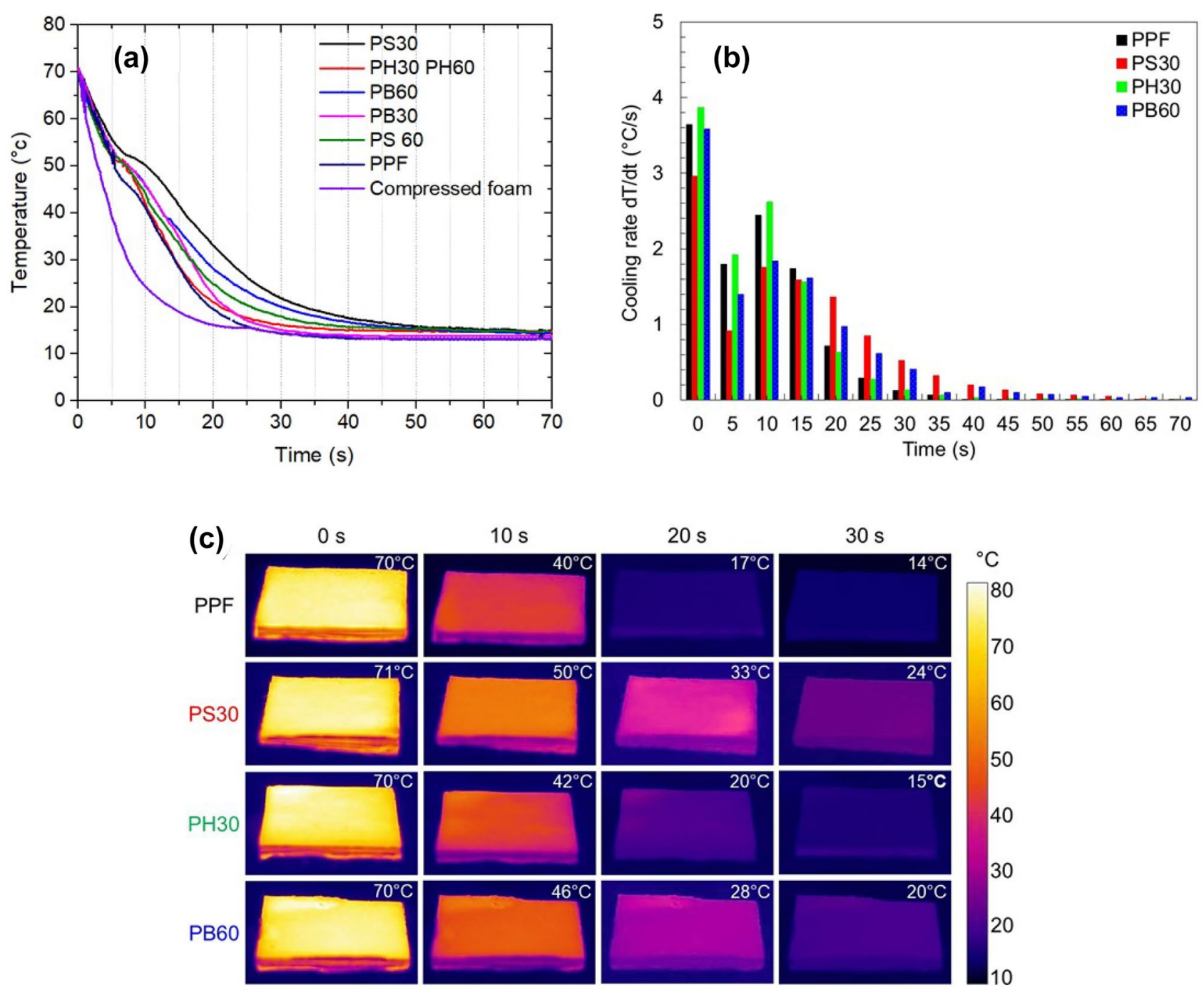

Fig. 9 (a) Cooling (temperature) profiles as a function of time for all PCM monoliths including the compressed foam. (b) Cooling rate as a function of time for PPF, PS30, PH30, and PB60 monoliths. (c) IR-camera images taken during cooling of PPF, PS30, PH30, and PB60 monoliths

is a simple but effective technique for estimating the utility of PCM materials. The method provides information about the amount of energy that can be absorbed and released by a material. The energy that can be absorbed is correlated to the enthalpy of melting, whereas the energy that can be released is associated with the enthalpy of crystallization $(\Delta \mathrm{Hc}$ in $\mathrm{J} / \mathrm{g}$ ). The DSC results are summarized in Table 4. Figure $\mathrm{S} 2$ indicates that both melting and crystallization or solidification curves show three thermal peaks for the PPF. Two of these originate from the paraffin wax (approximately at $42{ }^{\circ} \mathrm{C}$ and at $58^{\circ} \mathrm{C}$, solid-solid and solid-liquid transformations, respectively) and the other at $96{ }^{\circ} \mathrm{C}$ due to phase change of the polyolefin component.

As indicated by Yang et al. [58] in a very recent review article on composite PCM material technologies, the large latent heat of pure PCMs enables thermal energy storage. However, the cooling capacity and storage efficiency are limited by the relatively low thermal conductivity of these materials like waxes (lower than $0.5 \mathrm{~W} / \mathrm{m} \mathrm{K}$ ) when compared to nano-ceramics, graphene and metals $(\sim 100 \mathrm{~W} / \mathrm{m}$

Table 4 Glass transition, melting temperature, enthalpy of melting, and enthalpy of crystallization values obtained from the DSC measurements shown in Figure S2

\begin{tabular}{lllll}
\hline PCM top layer & $\boldsymbol{T}_{\mathbf{g}}\left({ }^{\circ} \mathbf{C}\right)$ & $\boldsymbol{T}_{\mathbf{m}}\left({ }^{\circ} \mathbf{C}\right)$ & $\Delta \boldsymbol{H}_{\mathbf{m}}(\mathbf{J} / \mathbf{g})$ & $\Delta \boldsymbol{H}_{\mathbf{c}}(\mathbf{J} / \mathbf{g})$ \\
\hline PPF (Parafilm®) & 38.4 & 51.2 & 112.3 & -110.4 \\
PB30 & 39.0 & 51.6 & 73.9 & -72.5 \\
PB60 & 40.0 & 53.7 & 67.5 & -66.3 \\
PS30 & 38.5 & 52.6 & 76.3 & -75.2 \\
PS60 & 39.3 & 54.5 & 68.8 & -66.3 \\
PH30 & 39.9 & 53.9 & 75.8 & -74.1 \\
PH60 & 40.2 & 54.7 & 65.8 & -64.5 \\
\hline
\end{tabular}


K). To achieve both high energy density and cooling capacity, PCMs having both high latent heat and high thermal conductivity are required. This can be done by compounding PCMs with high thermal conductivity materials but, compounding PCMs with thermal conductors reduces energy density (enthalpy of melting) due to their low heat capacity $(\sim 1 \mathrm{~J} / \mathrm{g} \mathrm{K})$ when compared to the typical PCM latent heat $(\sim 100 \mathrm{~J} / \mathrm{g})$. Hence, structural PCM material design should take into account both energy density and power density but also ensure that no leakage occurs. It must be noted that cooling capacity is not an intrinsic material property, and depends highly on geometry, boundary conditions, and temperature cycling [58]. Table 4 shows that indeed, both PS30 and PB60 have lower $\Delta \mathrm{Hc}$ values compared to pure PPF, but they perform much better in delaying cooling compared to the PPF which is an intrinsic PCM. Future studies will include detailed modeling works including percolation theories, while rendering the composite PCMs multifunctional such as electromagnetic shielding properties by using modified nanoscale carbon hybrid fillers [59-61]. It is also important to understand and monitor the dispersion dynamics of the particles in the PCM during the heating-cooling cycles, newly developed technologies such as in situ liquid phase TEM analysis can be highly suitable for these materials systems [27].

In summary, these flexible (see Figure S3 and the video file; Supplementary Information), thermally conductive and stable PCM composites produced by solvent-free processes with easy scale-up potential can be very useful for different energy management systems ranging from modern electronic devices to energy savings in buildings $[62,63]$.

\section{Conclusions}

A new paper-like composite PCM structure was fabricated by hydraulic pressing a 1-cm-thick polyimide foam over an aluminum foil surface. Before pressing, the top surface of the polyimide foam was covered with a Parafilm ${ }^{\circledR} /$ ceramic composite PCM film and the bottom layer with a pure Parafilm ${ }^{\circledR}$. Upon compression, both the composite and the pristine PCMs were impregnated into the foam even if it irreversibly collapsed into a thin porous structure. For the top PCM layer, we compounded the Parafilm ${ }^{\circledR}$ with different concentrations of high- $k$ nano-BN, micro-SiC particles and their hybrids in order to improve the thermal performance. The lower PCM layer ensured a very strong adhesion of the compressed foam to the $\mathrm{Al}$ foil. Detailed infrared imaging indicated that the monoliths containing $30 \mathrm{wt} \%$ micro-SiC had the best thermal energy storage capability compared to all other systems including BN/SiC hybrids. The next best thermal performance was observed with the $60 \mathrm{wt} \%$ nano-BN composite. Due to compression, the cellular structure of the polyimide foams collapsed irreversibly while being impregnated by the PCMs from both sides. High- $k$ fillers enabled excellent impregnation into the collapsed foam and maintained exceptional shape stability and wax leakage prevention characteristics. This work demonstrates a scale-up adaptable, solvent-free manufacturing method to prepare flexible paper-like PCM composites with good thermal properties and excellent temperature shape stability beyond the melting point of paraffin waxes. They can be easily applied on various metallic surfaces as coatings as well.

Supplementary information The online version contains supplementary material available at https://doi.org/10.1007/s42114-022-00426-1.

Acknowledgements We thank IIT Central Laboratories Facility for mechanical characterization experiments and electron microscopy and Ms. Lara Marini for assistance with thermal characterization experiments and Assing Scientific Instruments, S.p.A for porosimetry.

Funding This work received funding from the European Union's Horizon 2020 research and innovation program under Grant No. 801229 (HARMoNIC).

\section{Declarations}

Conflict of interest The authors declare no competing interests.

Open Access This article is licensed under a Creative Commons Attribution 4.0 International License, which permits use, sharing, adaptation, distribution and reproduction in any medium or format, as long as you give appropriate credit to the original author(s) and the source, provide a link to the Creative Commons licence, and indicate if changes were made. The images or other third party material in this article are included in the article's Creative Commons licence, unless indicated otherwise in a credit line to the material. If material is not included in the article's Creative Commons licence and your intended use is not permitted by statutory regulation or exceeds the permitted use, you will need to obtain permission directly from the copyright holder. To view a copy of this licence, visit http://creativecommons.org/licenses/by/4.0/.

\section{References}

1. Hendrix WR (1996) US Patent 3,249,561

2. Hou TH, Weiser ES, Siochi EJ, St. Clair TL (2004) High perform. Polym 16:487-504

3. Pan LY, Shen YX, Zhan MS, Wang K, Gao DL (2010) Visualization study of foaming process for polyimide foams and its reinforced foams. Polym Compos 31(1):43-50

4. Ma J, Wang K, Zhan M (2015) A comparative study of structure and electromagnetic interference shielding performance for silver nanostructure hybrid polyimide foams. RSC Adv 5(80):65283-65296

5. Silcox R, Bolton JS, Kim N, Cano R, Howerton B (2013) Development of polyimide foam for aircraft sidewall applications. In 51st AIAA Aerospace Sciences Meeting Including the New Horizons Forum and Aerospace Exposition. 213 
6. Papadopoulou EL, Morselli D, Prato M, Barcellona A, Athanassiou A, Bayer IS (2016) An efficient pure polyimide ammonia sensor. J Mater Chem C 4(33):7790-7797

7. Pan LY, Zhan MS, Wang K (2010) Preparation and characterization of high-temperature resistance polyimide foams. Polym Eng Sci 50(6):1261-1267

8. Liu XY, Zhan MS, Wang K, Li Y, Bai YF (2012) Preparation and performance of a novel polyimide foam. Polym Adv Technol 23(3):677-685

9. Gu W, Wang G, Zhou M, Zhang T, Ji G (2020) Polyimide-based foams: fabrication and multifunctional applications. ACS Appl Mater Interfaces 12(43):48246-48258

10. Kausar A (2021) Emerging polyimide and graphene derived nanocomposite foam: research and technical tendencies. J Macromole Sci Part A 1-16

11. Wang YY, Zhou ZH, Zhou CG, Sun WJ, Gao JF, Dai K, Li ZM (2020) Lightweight and robust carbon nanotube/polyimide foam for efficient and heat-resistant electromagnetic interference shielding and microwave absorption. ACS Appl Mater Interfaces 12(7):8704-8712

12. Wang YY, Sun WJ, Yan DX, Dai K, Li ZM (2021) Ultralight carbon nanotube/graphene/polyimide foam with heterogeneous interfaces for efficient electromagnetic interference shielding and electromagnetic wave absorption. Carbon 176:118-125

13. Kim J, Kim G, Kim SY, Lee S, Kim Y, Lee J, Kim J, Jung YC, Kwon J, Han H (2021) Fabrication of highly flexible electromagnetic interference shielding polyimide carbon black composite using hot-pressing method. Compos Part B Eng 109010

14. Guo J, Li X, Chen Z, Zhu J, Mai X, Wei R, Guo Z (2022) Magnetic NiFe2O4/polypyrrole nanocomposites with enhanced electromagnetic wave absorption. J Mater Sci Technol 108:64-72

15. Guo J, Li X, Liu H, Young DP, Song G, Song K, Guo Z (2021) Tunable magnetoresistance of core-shell structured polyaniline nanocomposites with 0-, 1-, and 2-dimensional nanocarbons. Adv Compos Hybrid Mater 4(1):51-64

16. Guo J, Chen Z, Abdul W, Kong J, Khan MA, Young DP, Guo Z (2021) Tunable positive magnetoresistance of magnetic polyaniline nanocomposites. Adv Compos Hybrid Mater 4:534-542

17. Lee D, Kim J, Kim S, Kim G, Roh J, Lee S, Han H (2019) Tunable pore size and porosity of spherical polyimide aerogel by introducing swelling method based on spherulitic formation mechanism. Microporous Mesoporous Mater 288:109546

18. Shi B, Ma B, Wang C, He H, Qu L, Xu B, Chen Y (2021) Fabrication and applications of polyimide nano-aerogels. Compos Part A Appl Sci Manuf 106283

19. Zhong A, Li J, Zhang Y, Zhang F, Wang T, Zhang G, Wong CP (2020) Low temperature microwave fabrication of threedimensional graphene/polyimide foams with flexibility strain responsivity. Compos Part A Appl Sci Manuf 137:105995

20. Cheng Y, Zhang X, Qin Y, Dong P, Yao W, Matz J, Ye M (2021) Super-elasticity at $4 \mathrm{~K}$ of covalently crosslinked polyimide aerogels with negative Poisson's ratio. Nat Commun 12(1):1-12

21. Ren X, Wang J, Sun G, Zhou S, Liu J, Han S (2020) Effects of structural design including cellular structure precision controlling and sharp holes introducing on sound absorption behavior of polyimide foam. Polym Test 84:106393

22. Lu X, Liu H, Murugadoss V, Seok I, Huang J, Ryu JE, Guo Z (2020) Polyethylene glycol/carbon black shape-stable phase change composites for peak load regulating of electric power system and corresponding thermal energy storage. Eng Sci 9(3):2534. https://doi.org/10.30919/es8d901

23. Shi J, Huang X, Guo H, Shan X, Xu Z, Zhao X, Zou R (2020) Experimental investigation and numerical validation on the energy-saving performance of a passive phase change material floor for a real scale building. ES Energy Environ 8:21-28. https://doi.org/10.30919/esee8c380
24. Zhou Y, Wu S, Ma Y, Zhang H, Zeng X, Wu F, Guo Z (2020) Recent advances in organic/composite phase change materials for energy storage. ES Energy Environ 9(8):28-40. https://doi. org/10.30919/esee8c150

25. Huang J, Luo Y, Weng M, Yu J, Sun L, Zeng H, Guo Z (2021) Advances and applications of phase change materials (PCMs) and PCMs-based technologies. ES Mater Manuf 13:23-39. https://doi.org/10.30919/esmm5f458

26. Hu X, Wu H, Liu S, Gong S, Du Y, Li X, Qu J (2021) Fabrication of organic shape-stabilized phase change material and its energy storage applications. Eng Sci 17:1-27. https://doi.org/10.30919/es8d474

27. Guo Y, Jiang Q, Peng B, Zan X (2020) Investigating dynamic processes of nanomaterials using in situ liquid phase TEM technologies: 2014-2019. Eng Sci 9:17-24. https://doi.org/10.30919/ es8d912

28. Ikutegbe CA, Farid MM (2020) Application of phase change material foam composites in the built environment: a critical review. Renew Sustain Energy Rev 131:110008

29. Sardari PT, Giddings D, Grant D, Gillott M, Walker GS (2020) Discharge of a composite metal foam/phase change material to air heat exchanger for a domestic thermal storage unit. Renew Energy 148:987-1001

30. Ghalambaz M, Zhang J (2020) Conjugate solid-liquid phase change heat transfer in heatsink filled with phase change materialmetal foam. Int J Heat Mass Transfer 146:118832

31. Zheng H, Wang C, Liu Q, Tian Z, Fan X (2018) Thermal performance of copper foam/paraffin composite phase change material. Energy Convers Manage 157:372-381

32. Han W, Ge C, Zhang R, Ma Z, Wang L, Zhang X (2019) Boron nitride foam as a polymer alternative in packaging phase change materials: synthesis, thermal properties and shape stability. Appl Energy 238:942-951

33. Wu J, Li J, Xu X, Yang L, Wu J, Zhao F, Li C (2009) Molten salts/ceramic-foam matrix composites by melt infiltration method as energy storage material. J Wuhan Univ Technol Mater Sci Ed. 24(4):651-653

34. Sandra F, Depardieu M, Mouline Z, Vignoles GL, Iwamoto Y, Miele P, Bernard S (2016) Polymer-derived silicoboron carbonitride foams for $\mathrm{CO} 2$ capture: from design to application as scaffolds for the in situ growth of metal-organic frameworks. Chem A Eur J 22:8346-8357

35. Gong S, Cheng X, Li Y, Shi D, Wang X, Zhong H (2019) Enhancement of ceramic foam modified hierarchical A12O3@ expanded graphite on thermal properties of 1-octadecanol phase change materials. J Energy Storage 26:101025

36. Atta OM, Manan S, Ul-Islam M, Ahmed AAQ, Ullah MW, Yang G (2021) Silver decorated bacterial cellulose nanocomposites as antimicrobial food packaging materials. ES Food Agrofor 6:12-26. https://doi.org/10.30919/esfaf590

37. Al-Harbi N, Hussein MA, Al-Hadeethi Y, Umar A (2021) Cellulose acetate-hydroxyapatite-bioglass-zirconia nanocomposite particles as potential biomaterial: synthesis, characterization, and biological properties for bone application. Eng Sci 17:70 82. https://doi.org/10.30919/es8d528

38. Zhao S, Pei L, Li H, Ma Y, Lian Q, Zhou S, Wang Z (2020) Research progress in toughening modification of polybenzoxazine. Eng Sci 14:14-26. https://doi.org/10.30919/es8d1150

39. Vyas S, Shukla A, Shivhare SJ, Bagal S, Upadhyay N (2021) High performance conducting nanocomposites polyaniline (PANI)-CuO with enhanced antimicrobial activity for biomedical applications. ES Mater Manuf 15:46-52. https://doi.org/10. 30919/esmm5f468

40. Yu Z, Bai Y, Wang JH, Li Y (2021) Effects of functional additives on structure and properties of polycarbonate-based composites filled with hybrid chopped carbon fiber/graphene nanoplatelet 
fillers. ES Energy Environ 12(2):66-76. https://doi.org/10.30919/ esee8c434

41. Sun L, Liang L, Shi Z, Wang H, Xie P, Dastan D, Fan R (2020) Optimizing strategy for the dielectric performance of topologicalstructured polymer nanocomposites by rationally tailoring the spatial distribution of nanofillers. Eng Sci 12(5):95-105. https://doi. org/10.30919/es8d 1148

42. Zhang D, Sun J, Lee LJ, Castro JM (2020) Overview of ultrasonic assisted manufacturing multifunctional carbon nanotube nanopaper based polymer nanocomposites. Eng Sci 10(14):35-50. https://doi.org/10.30919/es5e1002

43. Zhao B, Liang L, Bai Z, Guo X, Zhang R, Jiang Q, Guo Z (2021) Poly (vinylidene fluoride)/Cu@ Ni anchored reduced-graphene oxide composite films with folding movement to boost microwave absorption properties. ES Energy Environ 14:79-86. https://doi. org/10.30919/esee8c488

44. Zhao Y, Niu M, Yang F, Jia Y, Cheng Y (2019) Ultrafast electro-thermal responsive heating film fabricated from graphene modified conductive materials. Eng Sci 8(4):33-38. https://doi.org/10.30919/es8d501

45. Yang H, Li Q, Wang Z, Wu H, Wu Y, Cheng X (2021) Effect of different sintering additives on the microstructure, phase compositions and mechanical properties of $\mathrm{Si} 3 \mathrm{~N} 4 / \mathrm{SiC}$ ceramics. ES Mater Manuf 15:65-71. https://doi.org/10.30919/esmm5f487

46. Yang H, Li Q, Wang Z, Wu H, Wu Y, Hou P, Cheng X (2021) Effect of graphene on microstructure and mechanical properties of Si3N4/SiC ceramics. ES Mater Manuf 12:29-34

47. Liu H, Yan Z, Sun Z, Li A, Guo Z, Qian L (2021) Highly efficient synthesis of hexagonal boron nitride nanofibers with high specific surface area. ES Mater Manuf. https://doi.org/10.30919/esmm5f561

48. Du B, Zhang D, Qian J, Cai M, He C, Zhou P, Shui A (2021) Multifunctional carbon nanofiber-SiC nanowire aerogel films with superior microwave absorbing performance. Adv Compos Hybrid Mater 4:1281-1291

49. Zhang X, Kim Y, Kim D, Liu M, Erramuspe IBV, Kaya GB, Cho $\mathrm{H}$ (2020) Shape-stabilized phase change material by a synthetic/ natural hybrid composite foam with cell-wall pores. ACS Appl Energy Mater 4(1):416-424

50. Bayer IS, Biswas A, Ellialtioglu G (2011) Fabrication of super water repellent silver flake/copolymer blend films and their potential as smart fabrics. Polym Compos 32(4):576-585

51. Clausi M, Bayer IS (2021) In-situ graphene alignment in selfsealing stretchable films for efficient thermal interface materials. Nano Select 2(2):433-446

52. Kasoju N, Kubies D, Kumorek MM, Křǐž J, Fábryová E, Machová LK, Rypáček F (2014) Dip TIPS as a facile and versatile method for fabrication of polymer foams with controlled shape, size and pore architecture for bioengineering applications. PloS One 9(10):e108792

53. Liu XY, Zhan MS, Wang K, Li Y, Bai YF (2012) Preparation and performance of a novel polyimide foam. Polym Adv Technol 23:677-685

54. Williams MK, Weiser ES, Fesmire JE, Grimsley BW, Smith TM, Brenner JR et al (2005) Effects of cell structure and density on the properties of high performance polyimide foams. Polym Adv Technol 16:167-174

55. Coates J (2006) Interpretation of infrared spectra, a practical approach. Encyclopedia of analytical chemistry: applications, theory and instrumentation. John Wiley \& Sons Ltd, Chichester 10815-10837

56. Tandon GP, Weng GJ (1988) A theory of particle-reinforced plasticity. J Appl Mech 55(1):126-135. https://doi.org/10.1115/1. 3173618

57. Friedlander SK, Ogawa K, Ullmann M (2001) Elasticity of nanoparticle chain aggregates: implications for polymer fillers and surface coatings. Powder Technol 118(1-2):90-96

58. Yang T, King WP, Miljkovic N (2021) Phase change materialbased thermal energy storage. Cell Rep Phys Sci 2(8):100540

59. Wu H, Zhong Y, Tang Y, Huang Y, Liu G, Sun W, Guo Z (2021) Precise regulation of weakly negative permittivity in $\mathrm{CaCu}-$ 3Ti4O12 metacomposites by synergistic effects of carbon nanotubes and grapheme. Adv Compos Hybrid Mater 1-12. https:// doi.org/10.1007/s42114-021-00378-y

60. Qi G, Liu Y, Chen L, Xie P, Pan D, Shi Z, Guo Z (2021) Lightweight Fe3C@ Fe/C nanocomposites derived from wasted cornstalks with high-efficiency microwave absorption and ultrathin thickness. Adv Compos Hybrid Mater 4(4):1226-1238

61. Hu X, Wu H, Lu X, Liu S, Qu J (2021) Improving thermal conductivity of ethylene propylene diene monomer/paraffin/expanded graphite shape-stabilized phase change materials with great thermal management potential via green steam explosion. Adv Compos Hybrid Mater 4:478-491

62. Naderizadeh S, Heredia-Guerrero JA, Caputo G, Grasselli S, Malchiodi A, Athanassiou A, Bayer IS (2019) Superhydrophobic coatings from beeswax-in-water emulsions with latent heat storage capability. Adv Mater Interfaces 6(5):1801782

63. Xie Y, Yang Y, Liu Y, Wang S, Guo X, Wang H, Cao D (2021) Paraffin/polyethylene/graphite composite phase change materials with enhanced thermal conductivity and leakage-proof. Adv Compos Hybrid Mater 4:543-551

Publisher's Note Springer Nature remains neutral with regard to jurisdictional claims in published maps and institutional affiliations. 